\title{
FACILITATING STATISTICAL LITERACY FOR EVIDENCE-BASED NURSING PRACTICE: AN ACTIVE-LEARNING APPROACH
}

\author{
Alex Bux \\ Pace University, New York, USA \\ Abux@pace.edu
}

\begin{abstract}
A critical component of the nursing education curriculum is facilitating evidence-based practice, which is the judicious use of evidence toward effective patient care. Among the knowledge and skill sets required, is statistical literacy, which is generally perceived to be difficult, resulting in learning outcomes that are lacking. This paper presents a student-centered approach to teaching statistical literacy, in which students are engaged in individual and group critique and analysis of scientific research articles. Students are facilitated to make meaningful connections. In general, students are motivated and engaged, and by addressing the broader research context, the variables and their relationships become more meaningful, and hence there is greater conceptual grasp of statistics, which can result in transferrable knowledge and skills. This active-learning approach facilitates a meaning-making experience, which improves self-efficacy, and makes learning more interesting and meaningful, rather than mechanical and anxiety-driven. More active-learning strategies should be implemented and formally assessed.
\end{abstract}

\section{INTRODUCTION}

A critical component of the nursing education curriculum is facilitating evidence-based practice, which is the judicious use of evidence toward effective decision-making and patient care. Among the knowledge and skill sets required, is statistical literacy, which is generally perceived to be difficult, resulting in learning outcomes that are lacking. Underpinning statistical literacy is the ability to interpret and critically evaluate statistical information and data-based arguments, and evaluate different perspectives relative to statistical information (Hassad 2015; Garfield \& Chance 2009). As noted by Mackey and Bassendowski (2017), evidence-based practice is relevant to all levels of nursing education and "is a way for the nursing discipline to minimize the theory to practice gap" (p. 51).

Increasingly nurses are being challenged to develop meaningful and effective interventions that address the health concerns of a diverse and multicultural society (Woods-Fugante \& Magyary, 2010). To accomplish this task, nurses need to be prepared to conduct scientific research and to understand the significance of research findings before they can integrate these into practice. The earliest reference to evidence-based practice (EBP) is generally attributed to Florence Nightingale, an eighteenth century nurse and researcher, known for her work during the Crimean war (Mackey \& Bassendowski, 2017). Nonetheless, EBP resided with the medical profession until the 1970's when the nursing profession, particularly in the U.S.A., became more directly involved (Hill, Fell, Kronenfeld, \& Nail-Chiwetalu, 2007). Influencing the expansion and adoption of EBP by other health care professions was a call for greater emphasis on accountability for patient care at all levels (Walsh, 1997). Associated with this, was the expanded role of the nurse as a coordinator of patient care and independent practitioner (Fairman, Rowe, Hassmiller, \& Shalala, 2011). More importantly, with the rapidly growing body of nursing research data, the expectation was that nurses must develop the expertise to critically appraise the evidence toward optimal patient care (LaSala, Connors, Pedro, \& Phipps, 2007). In effect, this has changed the climate and culture of nursing to one where nurses are now more directly involved in clinical decision-making (Jaafarpour \& Khani, 2011).

Additionally, given the varying levels of complexity of research data and research designs, effective use of the evidence requires quantitative literacy and statistical competence (Hassad, 2007; Cox, 1997). Over the past two decades, in particular, there has been growing importance attached to the teaching of statistics and research methods as core components of the nursing curriculum at both the undergraduate and graduate levels (Ciliska, 2005). This has become even more compelling for advance practice nursing, including clinical nurse specialists and nurse practitioners. The importance in this regard centers on their scope of practice, which allows for independent practice including assessment, diagnosis, planning, treatment, and evaluation. 


\section{OBJECTIVE AND RATIONALE}

This paper presents a student-centered approach for teaching statistical literacy for evidence-based practice using an integrated curriculum and case-based methodology. Statistical literacy is critical to the evaluation of the evidence presented in research articles, so that practitioners can better determine the applicability to specific clinical contexts.

\section{THEORETICAL FRAMEWORK}

The theoretical approach underlying this course is primarily centered on constructivism which has long been identified as relevant to the teaching of research and statistical literacy (Garfield, 1995). The core principles of this approach are that learners process and make sense of new information based on prior knowledge and understanding, and that learning is an active process of integrating current and prior information, knowledge, and understanding toward constructing meaning (Naylor \& Keogh, 1999).

This constructivist approach to fostering statistical literacy seeks to facilitate a meaningmaking experience for students, which empowers them, and makes learning more interesting and meaningful, rather than mechanical and anxiety-driven, which is typically associated with the learning of statistics. Furthermore, according to Hassad (2011), teaching statistics using the constructivist-based approach can be effective for facilitating evidence-based practice. Specifically, this approach emphasizes the data context and the unifying role of statistics in integrating the study theory, research design, and practice domain. As Hassad notes, "in the constructivist context, the instructor utilizes active learning strategies to scaffold activities and tasks (so that students can progress from the simple to the complex), explore information, discover concepts, and construct knowledge and meaning" (p. 3). This represents a shift to a more concept-based curriculum, an approach that is widely recommended to meet the changing needs of nursing education (Brandon \& All, 2010).

\section{PEDAGOGICAL APPROACH}

Statistics is addressed in the quantitative methods module of a hybrid graduate level (one semester, three-credit) research methods course taught primarily to students in a nurse practitioner program. The primary objective of this module is to foster a deep understanding of statistical methods and quantitative research, in the context of evidence-based practice.

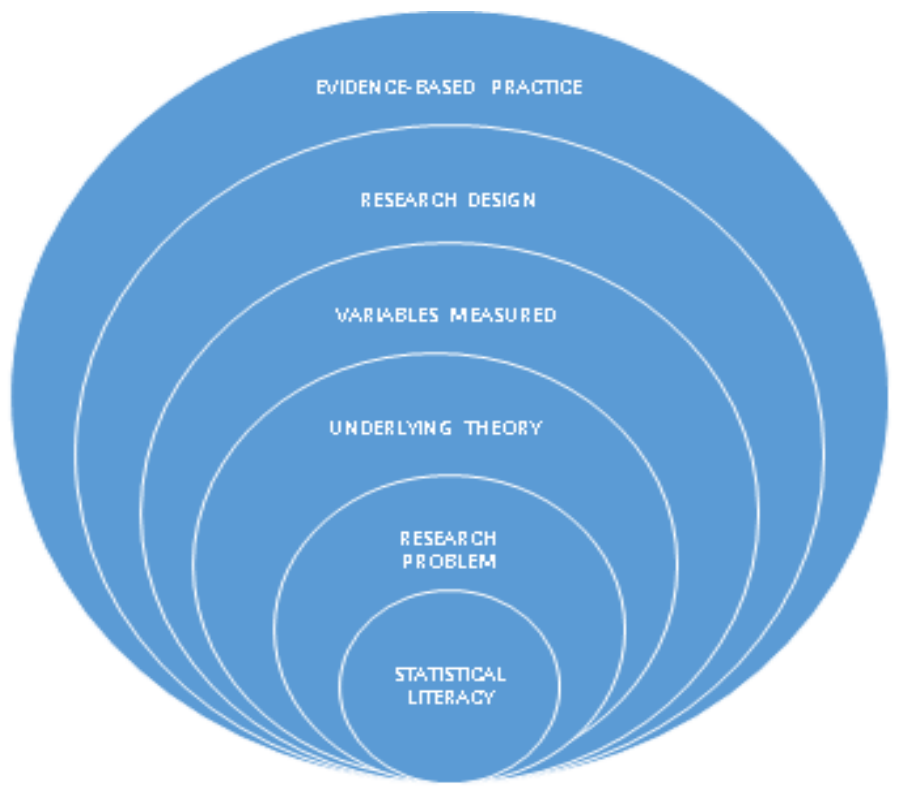

Figure 1: Conceptual Framework of Course Content for Statistical Literacy

Albeit, a single module, the course philosophy is premised on the understanding that in order for students to understand the statistical component (a part) they must first understand the entire 
study (the whole; see Figure 1). In other words, there is an emphasis on deductive reasoning. In this regard, the content of this module centers around a research article carefully selected to facilitate an understanding of key statistical and methodological concepts. This material is provided to the students in advance with critique guidelines encompassing the introduction and literature review, objective, methods, results, and discussion sections of the paper. Specifically, the guidelines addressing the statistical material are outlined in Table 1.

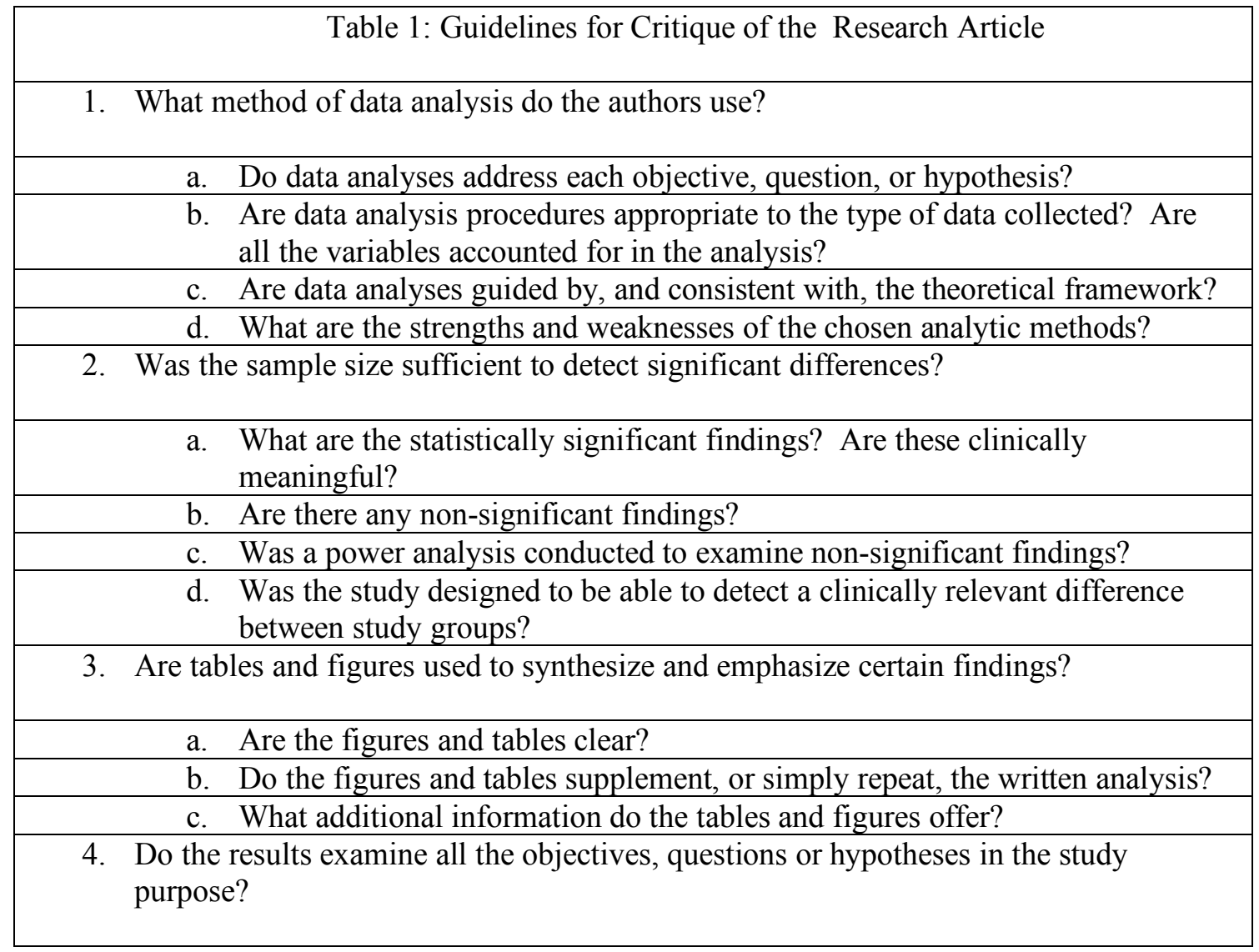

For the classroom component, students are engaged in small-group or cooperative learning exercises. This exercise engenders discussion about content knowledge, research design, statistical analysis, potential confounding, as well as reliability and validity of the results. General and specific limitations and strengths are also addressed. The instructor facilitates the discussion by posing specific questions to help students to make meaningful connections, and address misconceptions. The emphasis is on conceptual understanding rather than the computations underlying statistical methods. The assessment of learning outcomes is based on an online narrative which students are required to post following the classroom discussion. This allows them time to reflect on the discussions and collaborative learning, and develop a more meaningful response. Such narratives allow students to think critically about the material and integrate information across the study toward a deeper and more applied understanding of the material. A rubric based on the above dimensions is used to assess their responses. The final overall course assessment includes a culminating team project, which requires students to identify and evaluate relevant research evidence to support a particular clinical problem.

\section{OUTCOMES}

In general, students are motivated and engaged, and by addressing the broader research context (see Table 2), the variables and their relationships become more meaningful, and hence 
there is a greater conceptual grasp of the statistical analysis, which can result in transferrable knowledge and skills. This active-learning, case-based approach to fostering statistical literacy facilitates a meaning-making experience for students, which enhances self-efficacy (regarding the interpretation and use of statistical data), and makes learning more interesting and meaningful, rather than mechanical and anxiety-driven, which is typically associated with the learning of statistics (Onwuegbuzie \& Wilson, 2003).

\begin{tabular}{|l|l|}
\hline \multicolumn{2}{|c|}{ Table 2: Statistical Literacy Outcomes for Evidence-Based Practice } \\
\hline 1. & Recognize the importance of and understand the research problem and wider study context \\
\hline 2. & $\begin{array}{l}\text { Identify and understand the research variables and the study hypothesis/objective/research } \\
\text { questions }\end{array}$ \\
\hline 3. & Understand the theoretical or conceptual framework of the study \\
\hline 4. & Appreciate and understand the role of descriptive statistics in research \\
\hline 5. & Appreciate and understand the role of inferential statistics \\
\hline 6. & Select appropriate statistical tests \\
\hline 7. & Interpret and understand statistical results (including strengths and limitations) \\
\hline 8. & $\begin{array}{l}\text { Differentiate between association and causation based on the study design and methodology } \\
\text { (experimental and non-experimental) }\end{array}$ \\
\hline 9. & Identify relevant data to support evidence-based practice \\
\hline 10. & Evaluate research evidence for reliability and validity \\
\hline 11. & Determine the applicability of the research evidence to the clinical context \\
\hline 12. & $\begin{array}{l}\text { Enhance self-efficacy (that is students' belief in their capability to critique a research paper, } \\
\text { interpret, and use the evidence for clinical decision-making) }\end{array}$ \\
\hline
\end{tabular}

\section{DISCUSSION AND IMPLICATIONS}

This paper describes a plausible pedagogical approach using quantitative research articles to facilitate statistical literacy for graduate nursing students. The preliminary results suggest that this instructional methodology may be beneficial to teaching statistics, and therefore, should be further evaluated, and applied more broadly. The instructional model emphasizes concepts rather than mathematical procedures, and thereby engenders a friendlier and more engaging environment which can foster deep learning and hence transferrable knowledge and skills. Moreover, this teaching technique can allow students to recognize and appreciate the value of statistics to evidence-based practice. As well, it can stimulate interest in statistics, enhance self-efficacy and lead students to pursue further studies in statistics, which can also help to increase the number of nurse practitioners and educators involved in research and data analysis. Central to this pedagogical strategy is the assessment approach, which should address critical thinking together with integration, evaluation, and application of evidence. In this regard, cooperative or small-group learning, oral presentations, reflective exercises, critique of research articles, and report writing can be helpful as active learning strategies (Hassad, 2011).

Such active-learning strategies can be promoted at two levels; formal degree training and professional development or continuing education programs for nurses (Chaffin \& Maddux, 2004). This model can also be used for developing conversational and nurse-friendly software programs which can help to automate the process of identifying and evaluating evidence in a more structured manner, and allow for greater consistency in the use of evidence in clinical practice.

Indeed, more formal and objective evaluation of this pedagogical model for promoting statistical literacy and evidence-based practice, is required including comparison with data from students who were exposed to other teaching methodologies. Notably, other disciplines have documented this model as a best practice, in this regard (Tishkovskaya \& Lancaster, 2010). Finally, it is worth reiterating that statistical literacy is critical for nursing practice, at all levels, especially given the increasing complexity of patient care needs, and the rapidly growing body of healthcare research, which must be appropriately and effectively used if optimum patient care is to be provided. 


\section{ACKNOWLEDGEMENTS}

Special thanks to Dr. Winifred Connerton and the faculty and administration of Pace University, Nurse Practitioner Program, for their support, and the opportunity to share and develop my expertise in this area. And my deep appreciation to Dr. Rossi Hassad, Professor, Mercy College, New York, for the mentorship and guidance provided during the process and completion of this paper.

\section{REFERENCES}

Brandon, A. F., \& All, A. C. (2010). Constructivism theory analysis and application to curricula. Nursing Education Perspectives, 31(2), 89-92.

Chaffin, A. J., \&Maddux, C. D. (2004). Internet teaching methods for use in baccalaureate nursing education. Computers, Informatics, Nursing, 22(3), 132-142.

Ciliska, D. (2005). Educating for evidence-based practice. Journal of Professional Nursing, 21(6), 345-350.

Clair, K. S., \& Chihara, L. (2012). Team-based learning in a statistical literacy class. Journal of Statistics Education, 20(1), 1-20.

Enders, F. B., \& Diener-West, M. (2006). Methods of learning in statistical education: A randomized trial of public health graduate students. Statistics Education Research Journal, 5(1), 5-19.

Fairman, J. A., Rowe, J. W., Hassmiller, S., \& Shalala, D. E. (2011). Broadening the scope of nursing practice. New England Journal of Medicine, 364(3), 193-196.

Garfield, J. (1995). How students learn statistics. International Statistical Review, 63(1), 25-34.

Garfield J., Chance, B. (2009). Assessment in statistics education: Issues and challenges. Mathematical Thinking and Learning, 2(1-2), 99-125.

Hagen, B., Awosoga, O., Kellett, P., \& Dei, S. O. (2013). Evaluation of undergraduate nursing students' attitudes towards statistics courses, before and after a course in applied statistics. Nurse education today, 33(9), 949-955.

Hassad, R. A. (2015). Variability in the Teaching of Statistical Literacy: A Case of Pedagogical Dissonance. In Proceedings of the Satellite Conference of the International Association for Statistical Education (IASE).

Hassad, R. A. (2011). Constructivist and behaviorist approaches: Development and initial evaluation of a teaching practice scale for introductory statistics at the college level. Numeracy, 4(2), 1-33.

Hassad R. A. (2007). Development and validation of a scale for measuring instructors' attitudes toward concept-based or reform-oriented teaching of introductory statistics in the health and behavioral sciences. PhD dissertation, Touro University International.

Hill, B. S. W., Fell, D., Kronenfeld, M. L. S., \& Nail-Chiwetalu, B. (2007). Review for Librarians of evidence-based practice in nursing and the allied health professions in the United States. Journal of the Medical Library Association, 95(4), 394.

Hobden, S. (2014). When statistical literacy really matters: Understanding published Information about the HIV/AIDS epidemic in South Africa. Statistics Education Research Journal, 13(2), $72-82$.

Jaafarpour, M., \& Khani, A. (2011). The participation of nurses in decision making. Journal of Clinical and Diagnostic Research, 5(1), 16-19.

LaSala, C. A., Connors, P. M., Pedro, J. T., \& Phipps, M. (2007). The Role of the Clinical Nurse Specialist in Promoting Evidence-Based Practice and Effecting Positive Patient Outcomes. The Journal of Continuing Education in Nursing, 38(6), 262-270. http://doi:10.3928/0022012420071101-03

Mackey, A., \& Bassendowski, S. (2017). The history of evidence-based practice in nursing education and practice. Journal of Professional Nursing, 33(1), (January/February), 2017: 5155.

Naylor, S., \& Keogh, B. (1999). Constructivism in classroom: Theory into practice. Journal of Science Teacher Education, 10, 93-106. 
Onwuegbuzie, A.J., Wilson, V.A. (2003). Statistics anxiety: nature, etiology, antecedents, effects, and treatments: a comprehensive review of the literature. Teaching in Higher Education, 8,195-209.

Perkins, E. R. (1992). Teaching research to nurses: Issues for tutor training. Nurse Education Today, 12(4), 252-257.

Savard, A., \& Manuel, D. (2016). Teaching statistics: Creating an intersection for intra and interdisciplinary statistics. Statistics Education Research Journal, 15(2), 239-256.

Savery, J. R., \& Duffy, T. M. (2001). Problem Based Learning: An instructional model and its constructivist framework. In B. W. Wilson (Ed.), Constructivist learning environments: Case studies in instructional design (pp. 135-148). Englewood Cliffs, NJ: Educational Technology Publications.

Smith, N., Reid, A., \& Petocz, P. (2009). Representations of internationalisation in Statistics education. Journal of Statistics Education, 17(1), 1-16.

Tishkovskaya, S., \& Lancaster, G. A. (2010, July). Teaching strategies to promote statistical literacy: review and implementation. In Data and Context in Statistics Education: Towards an Evidence-Based Society. Proceedings of the Eighth International Conference on Teaching Statistics. Voorburg, The Netherlands: International Statistical Institute.

Walsh, M. (1997). Accountability and intuition: justifying nursing practice. Nursing Standard, 11(23), 39-41. http://dx.doi.org/10.7748/ns.11.23.39.s51

Williams, A. S. (2010). Statistics anxiety and instructor immediacy. Journal of Statistics Education, 18(2), 1-18.

Woods-Fugante, N., \& Magyary, D. L. (2010).Translational Research: Why Nursing's Interdisciplinary Collaboration Is Essential. Research and Theory for Nursing Practice, 24(1), 9-24. 